\title{
Implementing Shared Decision Making In Clinical Practice: Outcomes of a New Shared Decision Making Aid for Chronic Inflammatory Arthritis Patients
}

\author{
${ }^{1}$ Honorary Senior Clinical Lecturer, King's College, UK \\ ${ }^{2}$ Department of Community, Environmental and Occupational Medicine, UK \\ ${ }^{3}$ Department of Rheumatology and Rehabilitation, Ain Shams University, UK \\ ${ }^{4}$ North Middlesex University Hospital, London, UK \\ ${ }^{5}$ Department of Internal Medicine, Cairo University, Cairo, Egypt
}

Yasser El Miedany1,3*, Maha El Gaafary², Sally Sayed ${ }^{3}$, Deborah Palmer ${ }^{4}$ and Ihab Ahmed ${ }^{5}$

\section{Abstract}

Objective: To develop and evaluate an evidence-based shared decision making (SDM) aid for patients with chronic arthritic conditions to inform them about the pros and cons of their treatment options and to help them make an informed shared decision.

Methods: A multidisciplinary team defined criteria for the SDM as to design, medical content and functionality, particularly for elderly users. Development was according to the international standard (IPDAS). 174 patients with rheumatoid arthritis, ankylosing spondylitis and psoriatic arthritis, who were either treated or not yet treated, evaluated the tool, in a randomized controlled study, in comparison to control group composed of 172 patients treated according to standard methods.

Results: The SDM aid was developed to offer information about the disease, the risks and benefits of treatment. $98 \%$ of the patients included reported comprehensibility of $>85 / 100$. There was no significant difference between the online and paper format SDM aids. The patients' adherence to anti-rheumatic therapy was significantly $(p<0.1)$ higher in the SDM group, whereas stopping DMARDs for intolerability was significantly $(p<0.01)$ higher in the control group at 12 months of treatment.

Conclusion: This evidence-based SDM aid for inflammatory arthritis patients, developed according to IPDAS criteria, was found to be a simple, user-friendly tool which can be implemented in standard clinical practice. It offered the chronic arthritis patients evidence-based information about the pros and cons of treatment options, improved patients' understanding of the disease, communication with their treating clinician as well as ability to make an informed decision.

Keywords: Shared decision making; Rheumatoid arthritis; Ankylosing spondylitis; Psoriatic arthritis; Adherence

\section{Introduction}

Over the past few years, the involvement of patients in the shared decision making (SDM) regarding their management has moved from being a subject of debate to a recommendation [1-4]. The underlying ethical principles of the patients' role in their management, particularly in chronic conditions, coupled with the interest of consumers, professionals and policy makers underpinned this development. Shared decision-making has been defined as an approach where clinicians and patients communicate together using the best available evidence about healthcare decisions, where patients are supported to deliberately consider the available options and arrive at informed preferences about the best action, meanwhile it respects patient autonomy. An earlier White Paper stated "shared decision making will become the norm no decision about me without me" [5]. This paved the way for SDM to be an essential philosophy and practice underpinning the new health service internationally.

Decision aids are evidence-based tools designed to inform people of the potential benefit and harm of the treatment options, clarify their preferences and provide a shared decision-making structure for discussion at a clinic visit [6]. Whilst there are several SDM tools developed for various diseases including 'Prosdex' for cancer prostate, 'Bresdex' for surgical treatment of early breast cancer, and 'Amniodex' for amniocentesis for Down's Syndrome; little attention has been paid to chronic arthritic condition and the consideration in rheumatology has focused on rheumatoid arthritis (RA) [7]. Nearly one-third of RA patients surveyed for a recent report in the Journal of Rheumatology felt they had not been well enough informed to allow SDM. Furthermore, some of the disparities seen in RA outcomes were attributed to inequity in medication use [8]. However, it can be said that we are living in what seems like a golden age of chronic arthritis management, not only for RA but also for other conditions such as ankylosing spondylitis and psoriatic arthritis. This is credited to the explosion in treatment options and strategies, which has made remission a realistic target [9-11].

Though the principles of shared decision making are well documented, there is a lack of guidance regarding how to accomplish the approach in standard clinical practice. Furthermore, in rheumatology, research studies are needed to ascertain whether achieving greater

*Corresponding author: Yasser El Miedany, Consultant Rheumatologist, Darent Valley Hospital, Dartford, Kent, England, DA2 8DA, UK, Tel: 447900925363; Fax: +441322428415; E-mail: drelmiedany@rheumatology4u.com

Received: July 18, 2016; Accepted: July 23, 2016; Published: July 30, 2016

Citation: El Miedany Y, El Gaafary M, Sayed S, Palmer D, Ahmed I (2016) Implementing Shared Decision Making In Clinical Practice: Outcomes of a New Shared Decision Making Aid for Chronic Inflammatory Arthritis Patients. J Pat Care 2: 117. doi: 10.4172/2573-4598.1000117

Copyright: (c) 2016 El Miedany Y, et al. This is an open-access article distributed under the terms of the Creative Commons Attribution License, which permits unrestricted use, distribution, and reproduction in any medium, provided the original author and source are credited. 
Citation: El Miedany Y, El Gaafary M, Sayed S, Palmer D, Ahmed I (2016) Implementing Shared Decision Making In Clinical Practice: Outcomes of a New Shared Decision Making Aid for Chronic Inflammatory Arthritis Patients. J Pat Care 2: 117. doi: 10.4172/2573-4598.1000117

Page 2 of 6

involvement in decision making is associated with improved patient outcomes. Therefore, any new tool should be tested to assess for the patients' experience and outcomes.

\section{The aim of this work was to}

1. Assess a newly developed decision support aid, available both online as well as in paper format, developed to inform patients with chronic inflammatory conditions (rheumatoid arthritis, Psoriatic Arthritis and Ankylosing Spondylitis) about their ongoing active disease and the risks/benefits related to disease modifying drug therapy as well as biologic therapy available for their condition.

2. The ability of SDM aid to enhance clinical care. This will be carried out in a randomized control study based on the hypothesis that patient decision aids will be more effective than treatment decisions made based on standard formats; as well as

3. The assessment of a user-friendly platform for electronic SDM aid, equivalent to the paper SDM format; and how ubiquitous computing technology can improve the patients' compliance and adherence to therapy.

\section{Methods}

Driven by the Cochrane review of patient decision aids and the International Patient Decision Aids framework, which identify SDM tool as evidence-based tools designed to help people engage in deliberative treatment-related decision making by providing information on the options and outcomes relevant to health status, this project involved an overall three-phase SDM aid development $[12,13]$. The first phase included the development of the decision tool and review by expert faculty composed of: decision experts, patient representatives, policy makers, and patients living with Rheumatoid arthritis (RA)/Psoriatic arthritis (PsA)/Ankylosing Spondylitis (AS). The second phase was a pilot testing of the tool in both online and paper format styles. The third phase involved an evaluation of the decision support tool and its impact on the patients' adherence to therapy as well as service. Local ethical and methodological protocols for approval of the study were followed. All patients who shared in the study signed an informed consent according to the declaration of Helsinki.

\section{Phase I: Development of the decision support tool}

Driven by the Ottawa Decision Support Framework [14], the information, content, and format of the SDM aid were developed via a) systematic review of the available evidence, b) steering committee input, c) evaluation of the needs of individuals with RA/PsA/AS, and d) input from all key informants. The information gathered was incorporated into the SDM aid draft. The construction of the draft was based on the following components, according to the International Patient Decision Aids Standards (IPDAS) collaboration quality checklist $[15,16]$ framework and the guiding principles of the Ottawa Decision Framework [14], as follows:

1. Information about options and outcomes: the SDM aid includes a description of the clinical situation (i.e., the disease diagnosis) that has stirred the need to consider certain options and outcomes. The potential outcomes of untreated disease as well as each treatment option included were also described so that end-users will be able to understand what it may be like to experience each outcome. The functional impact of each outcome was also described $[12,17]$.
2. Presentation of outcomes probabilities: One of the consistent benefits of SDM aid is to create realistic expectations of outcomes and the likelihood of desirable and undesirable effects of all treatment options.

3. Values clarification: The personal importance of potential benefits and harms associated with each treatment option was gathered aiming at providing an insight into how values affect personal decision making about options. This was presented in the form of a 'weigh scale', showing the potential desirable/undesirable effects of each option. The participants were prompted to add any extra positive or negative factors important to them as well as check or shade each of these items in the 'weigh scale' to indicate their relative importance.

4. Coaching or Guidance (provided by illustrating the SDM process, including personal benefits and risks; clarifying level of knowledge and personal values; listing of current health practices; listing questions; indicating preferred role in decision making; and indicating current predisposition toward options [18].

5. Delivery the format of the SDM aid for participants was available in both online as well as a paper-based version.

6. Review and revisions to the SDM aid draft.

\section{Phase 2: Pilot test 1 (SDM acceptability assessment)}

The purpose of Pilot 1 is to ensure that the SDM aid was 1 . Clearly formatted, 2. Acceptable to patients, and 3. feasible for patients to complete (i.e. completion is with ease and time-efficient). Three groups of patients each composed of 30 RA, 29 AS and 31 PsA patients, diagnosed according to international agreed criteria were included in this part of the study [19-21]. They represented 3 phases of the disease process ( $30 \%$ early in the disease course $<2$ years), $35 \%$ disease duration $2-5$ years and $35 \%$ disease duration $>5$ years. They were of different age groups, with variable disease activity measures. All patients were about to start either disease modifying drug therapy or biologic therapy. The sample size of the patients included in this testing was based on a review by Hertzog, suggesting a range of 20-40 participants to allow for sufficient variability in acceptability assessment of an intervention [20] Time taken per patient for this process was in the range of 10-15 min. The SDM aid draft was amended in view of this pilot testing outcomes.

\section{Phase 2: Pilot test 2 (Field testing)}

The purpose of Pilot 2 is to field test the SDM tool in the standard clinical setting. A total of 174 patients (61 RA, 51 AS and 62 PsA) were included in this phase. All were diagnosed according to agreed published diagnostic criteria [19-21]. To develop both estimates of effect size and variance for larger size randomized control trials, the sample size was selected based on Hertzog's recommendation as well as the Cochrane data, based on a level of significance of alpha $=0.05$, power (1-beta) $=0.80$, a standard deviation of 0.81 and a correlation between pretest and posttest scores of $0.80[12,22]$. All patients were due to start a specific new treatment for their disease either disease modifying or biologic therapy.

The patients were randomized to receive the final version of the SDM aid either in paper or online format (available on: http://www. rheumatology4u.com/decissionmaking.html). Every patient had an appointment booked to speak with a site-designated health care professional about treatment options. In addition, disease activity was measured and the patient had blood testing to assess for inflammatory 
Citation: El Miedany Y, El Gaafary M, Sayed S, Palmer D, Ahmed I (2016) Implementing Shared Decision Making In Clinical Practice: Outcomes of a New Shared Decision Making Aid for Chronic Inflammatory Arthritis Patients. J Pat Care 2: 117. doi: 10.4172/2573-4598.1000117

Page 3 of 6

markers (ESR and CRP). Time taken per patient for this process was $30 \mathrm{~min}$.

Control group: A total of 172 patients (60 RA, 51 AS and 61 PsA), of matched sex, age and disease duration were included as a control group. The patients were assessed by the same designated health care professional per center. Information regarding their treatment options was given using the standard protocols. Information leaflet about the agreed medication were handed to every patient. Each subject had their disease activity measure recorded as well as a blood check to assess for inflammatory markers (ESR and CRP).

\section{Phase 3: Impact on patients' management}

All the patients in both the active and control groups were managed according to EULAR guidelines and were assessed on a 3 monthly basis for a total period of 12 months [9-11]. To avoid influencing the outcomes, all subjects were instructed not to discuss their treatment group assignments or therapies with their rheumatologists or other patients. Similarly, the clinicians were asked not to discuss group assignments with the patients.

All the patients in both groups were given access to a telephone advice line to contact if they sustain any flare up of their symptoms or a problem with their current medications. If required, the patients were reviewed earlier in a hot clinic and treatment was adjusted according to their disease activity status. The final version of the SDM aid was tested for its medical content, usefulness and user-friendliness. At the end of 12 months of management every patient participating in the study was asked to complete a questionnaire [23].

This questionnaire consisted of 5 items to assess: 1.The patient's perspective of the way their disease was monitored and discussed; 2.The patient's expectations for improvement and the credibility of the intervention whether in the SDM aid was used online or in paper format form. These scales were administered using numerical VAS (scale 0-10, where " 0 " equals not at all and " 10 " corresponds to the maximum of that measure)

The 5 items were asking the the patient about: Did the SDM aid: help you understand effect of the treatment on disease activity $(0=$ did not help, 10=helped very much), Did the SDM aid 2. motivate you to take medication $(0=$ did not help, $10=$ helped very much), 3 . Trust in the treating doctor $(0=$ no trust, $10=\max$ trust $), 4$. Concerns about the future $(0=$ no concern, $10=$ much concerned), 5 . Coping with daily life and the disease $(0=$ able to cope, $10=$ unable to cope). Comprehensibility, user-friendliness as well as understandability of both online SDM aid and paper format were assessed using visual analogue scale 0-10.

Adherence to Therapy: Adherence, as defined by Cramer et al. [24], was evaluated using the parameters of compliance and persistence. Compliance was estimated by the medication possession ratio (MPR) and persistence by the time from treatment initiation to discontinuation with no medication refill gap for a period of 30 days or more during the period of interest. MPR was defined as the ratio of actually available doses against the expected doses that the patient should possess over a fixed period of time. Study patients were rated as having good compliance if the annual MPR $\geq 80 \%$.

\section{Primary End Point}

1. Develop a SDM tool to promote and support informed arthritic patient-health care professional decision making about available treatment options, and conduct preliminary testing of this tool.
2. Compare the SDM aid to standard formats used in the day to day practice.

\section{Secondary End Points}

To assess the impact of implementing SDM aid in standard practice on treatment outcomes, treatment optimization and adherence to therapy as well as its impact on the service.

\section{Statistical Analysis}

Data collected was introduced to a database for data management and statistical analysis. Categorical variables are expressed as number and percentage i.e. frequency tables, while quantitative scaled variables are presented as mean and standard deviation. Comparison were carried out using Mann-Whitney $U$ test and Fisher's exact test where appropriate. Alpha error was always set at 0.05 . All statistical manipulation and analyses were performed using the 16th version of SPSS.

\section{Results}

The pilot version was designed as a Power point presentation (Microsoft Office 2010; Microsoft Corp., Redmond, WA). For PsA patients, this comprised a total of 34 pages ('slides') for disease modifying drugs and 37 pages for biologic therapy whereas it included 38 pages for AS patients. For RA patients it was split into 3 main sections; one (26 pages) for the disease modifying drug therapy; a second for anti-TNF (30 pages) and a third for other biologic therapy agents (33 pages). It offers the patient general information as to their disorder, the possible treatment options available, and the opportunity to balance the risks involved against the benefits. The patients can then weigh up the facts, enabling them to move towards a decision as well as reflect on their decision.

Users can thumb through the SDM aid and choose information tailored to their individual physical condition. For this purpose, action buttons on 'crossroads' pages enabled them to skip pages about topics they may consider less relevant. In addition, the user can be directed to information pertinent to the patient by choosing their disease stage (naive to either Disease modifying drug therapy or biologic therapy). To prevent the patients from 'getting lost' in the program, a 'breadcrumb trail' was added to indicate the progress of and position in, the aid. To further comply with the IPDAS criteria, the following items were added: date of last update, a statement the developers of the SDM aid would not benefit from whichever choice the patient would make based on the aid and references to the level of evidence for the various bits of information given in the SDM aid.

In addition the section in which patients can consider their own situation as to treatment options, risks and anxiety and reflect on that decision was elaborated. Some of the pages in the SDM aid were presented in figures. They illustrate the information supplied on the disease itself, the risk of non-treatment as well as expected benefits of the different lines of management. It includes an interactive part in the form of a grid which the patient can fill to help considering the pros and cons of management options.

174 patients were included as an active group for the assessment of this SDM aid whereas 175 patients were included as a control group. Patient characteristics are shown in (Table 1). On a scale from zero to 100 , 'user-friendliness' scored a median of 88 (interquartile range [IQR] 73-86), 'understandability' 89 (IQR 81-90), and 'feeling better informed' 84 (IQR 71-90). The vast majority of patients stated the SDM 
Citation: El Miedany Y, El Gaafary M, Sayed S, Palmer D, Ahmed I (2016) Implementing Shared Decision Making In Clinical Practice: Outcomes of a New Shared Decision Making Aid for Chronic Inflammatory Arthritis Patients. J Pat Care 2: 117. doi: 10.4172/2573-4598.1000117

Page 4 of 6

\begin{tabular}{|l|c|c|}
\hline \multicolumn{1}{|c|}{ Characteristic } & Study Group \\
\hline Number of Patients & $52.7 \pm 11.3$ \\
\hline Age (years) (mean \pm SD) & 61 & 172 \\
\hline Number of Rheumatoid Arthritis patients & 51 & 62 \\
\hline Number of Ankylosing Spondylitis patients & 60 \\
\hline Number of Psoritic Arthritis patients & 51 \\
\hline Functional Disability (RA): HAQ & $61.81 \pm 0.3$ \\
\hline Functional Disability (AS): BASFI & $8.81 \pm 0.4$ \\
\hline Functional Disability (PSA): CASQ-FI & $2.1 \pm 0.4$ \\
\hline DAS-28 score (mean \pm SD) & $4.7 \pm 0.7$ \\
\hline ASDAS (mean \pm SD) & $3.7 \pm 1.2$ \\
\hline Prevalence of +ve Rheumatoid factor & $51.8 \%$ \\
\hline Prevalence of +ve Anti-CCP & $7.79 \pm 0.4$ \\
\hline Number of patients on synthetic DMARDs therapy & $70.7 \%$ \\
\hline Number of patients on Biologic DMARDs therapy & $113 / 174(64.9 \%)$ \\
\hline
\end{tabular}

Table 1: Comparison of age and baseline clinical and laboratory data in study groups.

\begin{tabular}{|l|c|c|}
\hline \multicolumn{1}{|c|}{ Characteristic } & Online Format \\
\hline Number of Patients & $\mathbf{8 7}$ & \multicolumn{1}{|c|}{ Paper Format } \\
\hline Age (years) (mean \pm SD) & $\mathbf{8 7}$ & $32.8 \pm 11.3$ \\
\hline Number of Rheumatoid Arthritis patients & 26 \\
\hline Number of Ankylosing Spondylitis patients & 30 \\
\hline Number of Psoritic Arthritis patients & 26 \\
\hline User- Friendliness median (interquartile range [IQR]) & $88(73-86)$ \\
\hline Understandability: median (interquartile range [IQR]) & $89(81-90)$ \\
\hline feeling better informed: median (interquartile range [IQR]) & $87(71-90)$. \\
\hline
\end{tabular}

Table 2: Comparison between the online and paper shared decision making aid format.

\begin{tabular}{|l|c|c|}
\hline \multicolumn{1}{|c|}{ Parameter } & Active Group \\
\hline Adherence to medication & $155 / 174(89.1 \%)$ & Control group \\
\hline Stop medications by the patient because of intolerance & $11 / 174(6.3 \%)$ \\
\hline Number of procedures done in the clinic (over the study period) & $74 / 174(42.5)$ \\
\hline $\begin{array}{l}\text { Number of visits for flare up of the disease that required early assessment (over } \\
\text { the study period) }\end{array}$ & $43 / 174(24.7 \%)$ \\
\hline
\end{tabular}

* $p<0.05$

Table 3: Patients' reaction toward their illness and its management, by 12 months of therapy, in the active versus the control group.

aid offered additional value in their decision making and $99 \%$ found the figures on possible risks clarifying rather than frightening. $98 \%$ of the patients included reported comprehensibility of $>85 / 100$. There was no significant difference between the online and paper format SDM aids (Table 2).

\section{Adherence to Therapy}

Results of the patients reaction toward their illness and its management, by 12 months of therapy, in both the active versus the control group is shown in Table 3 . There was a significant main effect in the active group on subjects' mean displays of adherence to medications and coping with activities of daily living. Results of the study revealed that $89.6 \%$ patients in the active group were adherent to their drug therapy in comparison to $70.5 \%$ in the control group ( $\mathrm{p}<0.01)$. In addition to adherence to therapy, the active group was also less likely to stop their medication because of intolerance, more able to cope with their activities of daily living and have less concern about their future $(\mathrm{p}<0.01)$. In both groups, adherence to therapy was significantly correlated $(\mathrm{p}<0.01)$ to knowledge about current medications and the patient's involvement in the decision making.

\section{Discussion}

SDM is transforming medical practice at an international level, as providers, purchasers, policymakers, and patients explore opportunities to integrate patient-centered concepts into standards of care. Led by developments in the UK and USA, it makes patients' views and choices central to medical decision-making, applicable in short-term (e.g. infections), long-term (e.g. diabetes and arthritis), 'preference-sensitive' (e.g. menorrhagia) and screening (e.g. prostate testing) scenarios [25]. The development of this SDM aid was similar to those implemented in other medical realms, such as cancer of the breast, prostate, or lungs, however, it differs in that it focused on a chronic debilitating arthritic conditions rather than potentially life-threatening disorders [26-28].

Results of this work revealed that the developed SDM aid enabled the treating health care professional to share necessary information in an evidence-based, standardized format. These results are in agreement with the evidence available from 86 randomized trials, on other medical conditions, showing knowledge gain by patients, more confidence in decisions, more active patient involvement, and, in many situations, informed patients elect for more conservative treatment options [29]. For RA patients there are online SDM tools [6,30,31], which were developed mainly for biologic therapy. No SDM aids are yet available for disease modifying drug therapy.

The information offered in this SDM aid paid special attention to both joint damage and ability to carry out activities of daily living which are the main outcomes of direct impact on the patient's life. Considering the 
Citation: El Miedany Y, El Gaafary M, Sayed S, Palmer D, Ahmed I (2016) Implementing Shared Decision Making In Clinical Practice: Outcomes of a New Shared Decision Making Aid for Chronic Inflammatory Arthritis Patients. J Pat Care 2: 117. doi: 10.4172/2573-4598.1000117

Page 5 of 6

important outcomes and co-morbidities included in this tool, play a role in tailoring the information to the patient's need. In addition it may be a useful adjuvant in the communication between patient and the treating clinician. The IPDAS criteria [13] also describe "the possibility to view probabilities based on the patient's own situation" as one of the quality criteria.

Over the past years, there was a debate about the value of decision aids in improving the clinical decision making process [32]. Results of earlier studies revealed that decision aids did not appear to outperform comparative strategies in affecting patient satisfaction with decision making, anxiety, and health outcomes [33]. Furthermore, it was advised that decision aids should only be developed if evidence is available in sufficient amounts to underpin the information supplied for the various treatment alternatives. In contrast results of this work revealed that the cornerstones for good SDM aid are both supporting the process of deliberation, and the understanding that decisions should be influenced by exploring and respecting "what matters most" to patients as individuals. This exploration will in turn help the patients to develop informed preferences. Results of this work also elaborated the positive impact of SDM on the patients' adherence to therapy as well as costeffective impact on the service provided.

Achieving shared decision making depends on building a good relationship in the clinical encounter so that information is shared and patients are supported to deliberate and express their preferences and views during the decision making process [17]. Results of this work revealed that, after adjustments and appraisal by the patients, this SDM aid was considered user friendly, of additional value, and improved the patients understanding of their disease and its management. This was reflected on the patient-rheumatologist communication during clinic visits which improved significantly in the active group.

In conclusion, this evidence-based SDM aid for inflammatory arthritis patients was found to be a simple, user-friendly tool which can be implemented in standard clinical practice. It offered the chronic arthritis patients, evidence-based information about the pros and cons of treatment options, improved patients' understanding of the disease, communication with their treating clinician as well as ability to make an informed decision.

\section{Disclosure}

All authors have no relevant financial disclosures.

\section{Contributorship}

All authors had a substantial contribution to the conception and design of the study, drafting/ revising of the article and final approval of the version to be published.

\section{Acknowledgement}

We express thanks to all participants, our colleagues, research assistants and nurses for their cooperation and help to bring this research to its final conclusions. We would like to thank Mr. Omar El Miedany for Technical and admin support.

\section{References}

1. Schneider CE (1998) The practice of autonomy: patients, doctors, and medical decisions. New York: Oxford University Press.

2. Gwyn R, Elwyn G (1999) When is a shared decision not (quite) a shared decision? Negotiating preferences in a general practice encounter. Soc Sci Med 49:437-47.

3. Edwards A, Elwyn G (2001) Evidence based patient choice: inevitable or impossible. Oxford: Oxford University Press.

4. NICE guidelines: Medicines optimisation: The safe and effective use of medicines to enable the best possible outcomes.

5. Equity and excellence: Liberating the NHS, 2012.
6. Li L, Adam P, Townsend A, Lacaille D (2013) Usability testing of ANSWER: A web-based methotrexate decision aid for patients with rheumatoid arthritis. BMC Medical Informatics and Decision Making 13:131.

7. Epstein RM, Street RL (2011). Shared mind: communication, decision making and autonomy in serious illness. Annals of Family Medicine. 9 (5):454-61.

8. Hirsh JM (2014) Can shared decision making eliminate disparities in rheumatoid arthritis outcomes? J Rheum 41:1257-1259.

9. Singh JA, Furst DE, Bharat A, Curtis JR, Kavanaugh AF, et al. (2012) Update of the 2008 American College of Rheumatology recommendations for the use of disease-modifying anti-rheumatic drugs and biologic agents in the treatment of rheumatoid arthritis. Arthritis Care Res 64:625-39.

10. Braun J, van den Berg R, Baraliakos X, Boehm H, Burgos-Vargas, $R$ et al. (2011) Recommendations 2010 update of the ASAS/EULAR recommendations for the management of ankylosing spondylitis. Ann Rheum Dis 70: 896-904.

11. Gossec L, Smolen J, Gaujoux-Viala C, Ash Z, Marzo-Ortega, M et al. (2012) Recommendations European League against rheumatism recommendations for the management of psoriatic arthritis with pharmacological therapies. Ann Rheum Dis 71:4-12.

12. Stacey D, Bennett CL, Barry MJ, Col NF, Eden KB, et al. (2011) Decision aids for people facing health treatment or screening decisions. Cochrane Database Syst Rev 10: CD001431.

13. Elwyn G, Stacey D, Volk R, Edwards A, Coulter A et al. (2006) International Patient Decision Aids Standards (IPDAS) Collaboration: Developing a quality criteria framework for patient decision aids: Online International Delph Consensus Process. BMJ 333:417.

14. O'Connor AM, Tugwell P, Wells GA, Elmslie T, Jolly E, et al. (1998) A decision aid for women considering hormone therapy after menopause: decision support framework and evaluation. Pat Educ Couns 33:267-279.

15. International Patient Decision Aid Standards Collaboration 2006: Checklis for Judging the Quality of Patient Decision Aids. http://ipdas.ohri.ca/IPDAS_ checklist.pdf

16. Elwyn G, O'Connor A, Stacey D, Volk R, Edwards A, et al. (2006) International Patient Decision Aids Standards (IPDAS) Collaboration: Developing a quality criteria framework for patient decision aids: online international Delph consensus process. BMJ 333:417.

17. Elwyn G, Frosch D, Thomson R, Joseph-Williams N (2012) Shared decision making: A model for Clinical Practice. J Gen Intern Med 27: 1361-1367.

18. Ottawa Personal Decision Guide, 2-page interactive PDF

19. Aletaha D, Neogi T, Silman A, Funovits J, Felson D, et al. (2010) Rheumatoid arthritis classification criteria: An American College of Rheumatology/European League against rheumatism collaborative initiative. Ann Rheum Dis 69:15801588.

20. Zeidler H, Amor B (2011) The Assessment in Spondyloarthritis International Society (ASAS) classification criteria for peripheral arthritis and for spondyloarthritis in general: The spondyloarthritis concept in progress. Ann Rheum Dis 70:1-3.

21. Taylor W, Gladman D, Helliwell P, Marchesoni A, Mease P, et al. (2006) Classification criteria for psoriatic arthritis development of new criteria from a large international study. Arthritis Rheum 54: 2665-2673.

22. Hertzog M (2008) Considerations in determining sample size for pilot studies. Res Nurs Heatlh 31: 180-191.

23. El Miedany Y, El Gaafary M, Palmer D (2012) Assessment of the utility of visua feedback in the treatment of early rheumatoid arthritis patients: A pilot study. Rheumatol Int 32: 3061-3068.

24. Cramer JA, Roy A, Burrell A, Fairchild CJ, Fuldeore MJ, et al. (2008) Medication compliance and persistence: Terminology and definitions. Value Health 11: 4447.

25. Ubbink A, Knop D, Molenaar S, Goossens A (2008) Design and development of a decision aid to enhance shared decision making by patients with an asymptomatic abdominal aortic aneurysm. Patient Preference and Adherence 2: 315-322.

26. Molenaar S, Sprangers MA, Rutgers EJ, et al. (2001) Decision support for patients with early-stage breast cancer: Effects of an interactive breast cancer CDROM on treatment decision, satisfaction and quality of life. J Clin Oncol 19: 1676-87. 
Citation: El Miedany Y, El Gaafary M, Sayed S, Palmer D, Ahmed I (2016) Implementing Shared Decision Making In Clinical Practice: Outcomes of a New Shared Decision Making Aid for Chronic Inflammatory Arthritis Patients. J Pat Care 2: 117. doi: 10.4172/2573-4598.1000117

27. Chiew KS, Shepherd $\mathrm{H}$, Vardy J (2007) Development and evaluation of a decision aid for patients considering first-line chemotherapy for metastatic breast cancer. Health Expect 11: 35-45.

28. Holmes-Rovner M, Stableford S, Fagerlin A (2005) Evidence-based patient choice: A prostate cancer decision aid in plain language. BMC Med Inform Decis Making 5: 16.

29. Stacey D, Bennett C, Barry M, Col N, Eden K, et al. (2011) Decision aids for people facing health treatment or screening decisions. Cochrane Database of Systematic Reviews CD001431.
30. Fraenkel L, Peters E, Charpentier P (2012)A decision tool to improve the quality of care in Rheumatoid Arthritis. Arthritis Care Res (Hoboken) 64: 977-985.

31. West Michigan Rheumatology PLLC. "Research Inspiring Care": Patient Decision Aids.

32. Holmes-Rovner M, Nelson WL, Pignone M, et al. (2007) Are patient decision aids the best way to improve clinical decision making? Report of the IPDAS Symposium. Med Decis Making 27: 599-608.

33. O'Connor AM, Stacey D, Entwistle V, et al. (2003) Decision aids for people facing health treatment or screening decisions. Cochrane Database Syst Rev 3: CD001431. 